\title{
QUANTIFYING THE SECOND-ROUND EFFECTS OF SUP- PLY-SIDE SHOCKS ON INFLATION
}

\author{
Tibor HLÉDIK *
}

\begin{abstract}
:
This paper uses a small-scale dynamic rational expectations model based on an openeconomy version of Fuhrer-Moore-type staggered wage setting to quantify the secondround effects of selected supply-side shocks and of shocks to the nominal exchange rate on wages and subsequently on inflation. In order to analyse the desired reaction of the central bank to these shocks, optimal time-consistent policy rules are derived within the presented New-Keynesian framework. The conclusions presented in the paper suggest that the second-round effects of shocks to import prices and the nominal exchange rate on inflation should not be ignored in practical policy-making.
\end{abstract}

Keywords: monetary policy, optimal policy rules, inflation targeting

JEL Classification: E52, E31, F41

\section{Introduction}

The Czech Republic introduced its inflation targeting regime at the beginning of 1998. Being a small open economy under transition, the Czech economy has experienced several quite significant external and internal supply-side shocks and changes in the nominal exchange rate over the last few years. These have exerted a strong direct influence on inflation. Sudden changes in import prices and changes in administered prices largely explain the volatility of inflation (measured by CPI consumer price index) since 1998. The direct effects of these supply-side shocks on inflation are fairly easily identifiable. However, it is more difficult to quantify some of the indirect effects of these supply-side shocks on inflation and to derive how central banks should react to them.

The main goal of this paper is to quantify the second-round effects of some selected supply-side shocks and a shock to the nominal exchange rate on wages and subsequently on inflation measured in terms of both the gross domestic product

*) Czech National Bank, Na Př́́kopě 28, CZ - 11503 Prague 1 (e-mail: Tibor.Hledik@cnb.cz).

$\left.{ }^{\star *}\right)$ This article has been elaborated within the Czech National Bank's Economic Research Programme. I would like to express my gratitude to A. Blake for his assistance during the work on previous versions of the model on which this paper is based. In addition, I would like to thank A. Bulír, V. Kotlán, D. Laxton, M. Mandel, J. U. Söderström and J. Vlček for their useful comments and suggestions. Of course, all remaining errors and omissions are solely mine. 
(GDP) deflator and the CPI. The motivation to do so stems from the author's attempt to explain the determinants of the GDP deflator in the Czech Republic and find a behavioural link between the GDP deflator and the labour market. The analysis is carried transparently within a simple structural model framework based on rational expectations. It is assumed that nominal wage contracts are set according to the corresponding specification of the open economy version of the Fuhrer, Moore (1995) model. In the Fuhrer-Moore model it is assumed that nominal wage contracts are set in order to keep the resulting real wage close to the weighted average of the past and anticipated future level of real wages. In order to define the second-round effects arising from various shocks on inflation, it is assumed first that nominal wage contracts are derived - similarly to the prevailing practice in the Czech Republic with respect to the real wage deflated by the CPI. By assuming that a firm's competitive position is more closely linked with real wages deflated by the GDP deflator, for the model with an alternative wage contract specification it is assumed that nominal wages are negotiated with respect to real wages deflated by the GDP deflator. For the purposes of this paper the second-round effects on inflation (and other model variables) arising from any shock are defined as the difference between the dynamics of the models corresponding with these two alternative wage-contracting specifications, other things held equal. Given the high aggregation of the model and the fact that the equations are not derived within a dynamic general equilibrium framework, some important "second-round effects" of supply-side shocks and shocks to the nominal exchange rate on inflation - such as the income effect - are ignored.

The paper is structured into seven sections. The introduction is followed by a description of the main behavioural equations, including a discussion of some of the model-related specifics of the Czech economy. The next section is devoted to presenting the state space representation of the model. This is necessary for deriving the analytic solution of the model in terms of optimal rules and jump variables. The fourth section reports on the parameterisation of the model. Special emphasis is given in this section to the calibration of the Phillips curve for domestic prices. Knowledge of model equations and numerical values for elasticities makes it possible to present the solution of the model in the next section. In order to evaluate the dynamic properties of the model, the sixth section investigates the results based on impulse responses for selected supply-side and asset-price shocks for three optimal policy rules corresponding to different ad-hoc loss functions of the monetary authorities. The last section summarises the results.

\section{The Model}

A New-Keynesian small open-economy rational expectations model is used for the analysis. This is very similar in structure to the models presented in Blake, Westaway (1996), Batini, Haldane (1999), Batini, Yates (2001) and Svensson (1999). The model was calibrated on quarterly seasonally adjusted data and specified in "gap" form. This means that all variables are defined as deviations from their longrun equilibrium values ${ }^{1)}$ or, in the case of inflation, as deviations from the inflation target. The model equations are as follows:

1) Equilibrium values were determined using a generalised version of the Hodrick-Prescott (HP) filter in the case of non-stationary variables and set to "long-term" averages in the case of stationary variables. The generalised HP filter in comparison with the ordinary HP filter includes a penalty weight for a deviation of the filtered value of the examined variable from its exogenously determined long-run (steady-state) growth rate. This modification makes it possible to mitigate the well-known poor end-of-sample properties of the HP filter by setting the parameters of the filter to reflect some judgement about the long-run growth rate and cyclical position of the economy. 


$$
\begin{aligned}
& y_{t}=\alpha_{11} \cdot y_{t-1}+\alpha_{12} \cdot r_{t-2}+\alpha_{13} \cdot q_{t-1}+\alpha_{14} \cdot y_{t-1}^{*}+\varepsilon_{t} \\
& \pi_{t}^{d}=\alpha_{21} \cdot E_{t}\left(\pi_{t+1}^{d}\right)+\sum_{i=1}^{3} \alpha_{2 i+1} \cdot \pi_{t-1}^{d}+\alpha_{25} \cdot E_{t}\left(\Delta e_{t+1} \pi_{t+1}^{i m}\right)+\sum_{j=0}^{3} \alpha_{2 j+6} \cdot\left(\Delta e_{t-j} \pi_{t-j}^{i m}\right)_{+} \\
& +\alpha_{210} \cdot E_{t}\left(\pi_{t+1}^{a d m}\right)+\sum_{k=0}^{3} \alpha_{2 k+11} \cdot \pi_{t-k}^{a d m}+\sum_{l=0}^{3} \alpha_{215+l} \cdot y_{t-1}+\omega_{t} \\
& \pi_{t}^{c p i}=\alpha_{31} \cdot \pi_{t}^{d}+\alpha_{32} \cdot\left(\Delta e_{t}+\pi_{t}^{i m}\right)+\left(1-\alpha_{31}-\alpha_{32}\right) \cdot \pi_{t}^{a d m} \\
& e_{\mathrm{t}}=E_{t}^{p}\left(e_{t+1}\right)+\alpha_{41} \cdot i_{t}+\alpha_{42} \cdot i_{\mathrm{t}}^{\star}+\varphi_{t} \\
& E_{t}^{p}\left(e_{t}\right)=\alpha_{51} \cdot E_{t}\left(e_{t+1}\right)+\left(1-\alpha_{51}\right) \cdot e_{t-1} \\
& r_{t}=\alpha_{61} \cdot E_{t}^{P}\left(r_{t+1}\right)+\alpha_{62} \cdot i_{t}+\alpha_{63} \cdot E_{t}\left(\pi_{t+1}^{d}\right)+1_{t} \\
& E_{t}^{P}\left(r_{t+1}\right)=\alpha_{71} \cdot E_{t}\left(r_{t+1}\right)+\left(1-\alpha_{71}\right) \cdot\left(i_{t}-\pi 4_{t}^{d}\right) \\
& i_{t}=\Psi_{1} \cdot y_{t}+\Psi_{2} \cdot y_{t-1}+\Psi_{3} \cdot y_{t-2}+\Psi_{4} \cdot y_{t-3}+\Psi_{5} \cdot y_{t-4}+ \\
& +\Psi_{6} \cdot \pi_{t-1}^{d}+\Psi_{7} \cdot \pi_{t-2}^{d}+\Psi_{8} \cdot \pi_{t-3}^{d}+\Psi_{9} \cdot \pi_{t}^{i m}+\Psi_{10} \cdot \pi_{t-1}^{i m}+ \\
& +\Psi_{11} \cdot \pi_{t-2}^{i m}+\Psi_{12} \cdot \pi_{t-3}^{i m}+\Psi_{13} \cdot \pi_{t}^{a d m}+\Psi_{14} \cdot \pi_{t-1}^{a d m}+ \\
& +\Psi_{15} \cdot \pi_{t-2}^{a d m}+\Psi_{16} \cdot \pi_{t-3}^{a d m}+\Psi_{17} \cdot e_{t-1}+\Psi_{18} \cdot e_{t-1}+ \\
& +\Psi_{19} \cdot \Delta e_{t-1}+\Psi_{20} \cdot \Delta e_{t-2}+\Psi_{21} \cdot \Delta e_{t-3}+\Psi_{22} \cdot q_{t-1}+ \\
& +\Psi_{23} \cdot \varphi_{t}+\Psi_{24} \cdot y_{t}^{*}+\Psi_{25} \cdot i_{t-1}+\Psi_{26} \cdot \pi_{t}^{d f}+\Psi_{27} \cdot r_{t-1}+\varpi_{t} \\
& q_{t}=q_{t-1}+\Delta e_{t}+\pi_{t}^{d f}-\pi_{t}^{d} \\
& \varphi_{t}=\alpha_{101} \cdot \varphi_{t-1}+\xi_{t} \\
& \pi_{t}^{i m}=\alpha_{111} \cdot \pi_{t-1}^{i m}+\kappa_{t} \\
& \pi_{t}^{d f}=\alpha_{121} \cdot \pi_{t-1}^{d f}+\xi_{t} \\
& \pi_{t}^{a d m}=\alpha_{131} \cdot \pi_{t-1}^{a d m}+\tau_{t} \\
& y_{t}^{\star}=\alpha_{141} \cdot y_{t-1}^{\star}+\gamma_{t} \\
& i_{t}^{*}=\alpha_{151} \cdot i_{t-1}^{*}+\theta_{t}
\end{aligned}
$$

where $E_{t}(\circ)=$ expected value of variable $\circ$ based on the information set of economic agents available at time $t^{2)} ; y_{t}=$ Czech GDP; $r_{t}=$ proxy for the real interest rate with one year maturity (see the description later); $q_{t}=$ real exchange rate; $\pi_{t}^{d}=$ quarterly percentage change in the GDP deflator at factor $\operatorname{cost}^{3)} ; \pi 4_{t}^{d}=$ year-on-year per-

2) The information set includes the specification of all model equations, including the reaction function of the central bank and exogenous shocks up to time $t$.

3) The GDP deflator at factor costs is calculated directly from the GDP deflator by eliminating the impact of indirect taxes on the index. 
centage change in the GDP deflator at factor cost; $\pi_{t}^{a d m}=$ administered price index; $\pi_{t}^{c p i}=$ quarterly inflation rate measured in terms of the consumer price index; $\pi_{t}^{d f}=$ quarterly percentage change in the German GDP deflator; $\pi_{t}^{i m}=$ quarterly imported price inflation expressed in terms of the euro; $e_{t}=$ nominal exchange rate of the Czech koruna against the euro; $i_{t}^{*}=3$-month money market rate (Germany, later eurozone); $i_{t}=3$-month PRIBOR; $\varphi_{t}=$ risk premium; $y_{t}^{*}=$ foreign demand approximated with German GDP; $\varepsilon_{t}, \omega_{t}, \iota_{t}, \varpi_{t}, \xi_{t}, \kappa_{t}, \varsigma_{t}, \tau_{t}, \gamma_{t}, \theta_{t}=$ shock terms.

Equation (1) specifies a standard open-economy backward-looking IS curve. Output is a function of lagged output, the real interest rate with a two-quarter lag, the lagged real exchange rate and foreign demand (both with a one-quarter lag). From the specification of equations (6) and (7) it is clear that the real interest rate determination is based on a risk-neutral arbitrage condition on the financial markets and private agents form both forward-looking and adaptive expectations. In this way it is possible to examine the impact of a change in interest rates with longer maturity on aggregate demand and implicitly take into account expectational yield-curve effects on the dynamic properties of the model.

Equation (2) is a Phillips curve for domestic inflation derived from a FuhrerMoore-type (F-M) wage-contracting specification ${ }^{4}$ ) that has been modified for a small open economy. This modification ${ }^{5)}$ is based on the assumption that wage setters do not derive their nominal wage demand from a real product wage, as it is the case in the F-M specification, but rather from their real consumer wage. ${ }^{6}$ This assumption is very much in line with the past and current practice of how wages are negotiated in the Czech Republic. Indeed, trade unions always communicate their nominal wage demands in terms of some "plausible" future real wage growth increased by expected inflation. Equation (2), as will be shown later, gives rise to secondround effects of some selected supply-side shocks or nominal exchange rate shocks on domestic inflation via the wage-contracting channel. The following three equations served as the basis for deriving equation (2):

$$
\begin{gathered}
p_{t}^{d}=\lambda_{1} \cdot w_{t}+\lambda_{2} \cdot w_{t-1}+\lambda_{3} \cdot w_{t-2}+\left(1-\lambda_{1}-\lambda_{2}-\lambda_{3}\right) \cdot w_{t-3} \\
p_{t}^{c p i}=\alpha \cdot p_{t}^{d}+\beta \cdot\left(e_{t}+p_{t}^{i m}\right)+(1-\alpha-\beta) \cdot p_{t}^{a d m} \\
w_{t}-p_{t}^{c p i}=\chi_{0} \cdot E_{t}\left(w_{t+1}-p_{t+1}^{c p i}\right)+\chi_{1} \cdot\left(w_{t-1}-p_{t-1}^{c p i}\right)+ \\
+\chi_{2} \cdot\left(w_{t-2}-p_{t-2}^{c p i}\right)+\chi_{3} \cdot\left(w_{t-3}-p_{t-3}^{c p i}\right)+ \\
+\left(1-\chi_{0}-\chi_{1}-\chi_{2}\right) \cdot\left(w_{t-4}-p_{t-4}^{c p i}\right)+\Omega \cdot y_{t}
\end{gathered}
$$

Equation (15) is a standard mark-up equation based on the assumption that prices are determined as a weighted average of current and past nominal contract wages. The mark-up was set to zero, and the number of lags was chosen so as to ensure that the reduced-form equation (2) for the calibration/estimation exercise is

4) See Fuhrer and Moore (1995). Of course, the F-M wage-contracting specification is not based on an SDGE optimising framework and as such is not immune to the Lucas critique. It is, however, still useful in "deepening" the Phillips-curve coefficients in equation (2) and linking aggregate price dynamics with labour market behaviour.

5) In Blake, Westaway (1996) and Batini, Haldane (1999) the Phillips curves are derived from the same theoretical assumptions.

6) The real product wage is defined as the nominal contract wage deflated by the GDP deflator at factor cost. Similarly, the real consumer wage is defined as the nominal contract wage deflated by the consumer price index. 
of a sufficiently general form. The next equation defines the consumer price index as a weighted average of the GDP deflator at factor cost, import prices and administered prices. Equation (16) deserves some more attention given that it is based on an approximation. The consumer price index in the Czech Republic measures the price level of a consumption basket consisting of approximately 790 representative products and services. The current data collection practice of the Czech Statistical Office does not make it possible to differentiate between domestically produced and imported goods or services in the CPI. Therefore, the only price index on the righthand side of equation (16) that is unambiguously defined within the CPI is $p^{\text {adm }}$, the price index measuring administered prices. The weighted average of the other two indices, the GDP deflator at factor cost and the import price index, is an approximation for both domestically produced goods with some import content and imported final goods. Equation (17) is based on the assumption that real wages today depend on the weighted average of expected real consumer wages one period ahead and lagged (1-4 quarters) real wages. Real wages are, most importantly, positively related to the cyclical position of the domestic economy (approximated by the output gap).

Equation (2) is derived by summing equations (17) for time indices $t+1-i$ multiplied by $\lambda_{i}(i=1 \ldots 3)$ and equation (17) for $t-3$ multiplied by $1-\lambda_{1}-\lambda_{2}-\lambda_{3}$ and by substituting out $w_{i}$ and $p_{i}^{c p i}(i=t+1, t, t-1, t-2, t-3, t-4)$ using equations (15) and (16). The reduced-form coefficients expressed as a function of the parameters of equations (15) - (17) are available on request from the author. ${ }^{7}$ )

Equation (3) is obtained by taking the first difference of both sides of equation (16). Equation (4) is a standard uncovered interest-rate parity arbitrage condition. The expectation formation of the private sector is not assumed to be fully forwardlooking model-consistent, as is apparent from the specification of equation (5). Private agents' exchange rate expectations are modelled as a weighted average of forward-looking rational and backward-looking expectations. This modification in the UIP condition makes the nominal exchange rate, and consequently the model's dynamics, less "jumpy" and therefore more realistic.

Equation (6) is derived from an approximation of the risk-neutral arbitrage condition on the financial market for the real interest rate with one-year maturity, as

$$
\text { captured by the following equation: } r_{t}=\frac{1}{4 \cdot n+1} \cdot \sum_{s=0}^{\infty}\left(\frac{4 \cdot n}{4 \cdot n+1}\right)^{s} \cdot E_{t}\left(i_{t+s}-4 \cdot \pi_{t+1+s}^{d}\right)
$$

where $n$ is set to unity. ${ }^{8)}$ Equation (6) can be obtained by applying the expectation operator $E_{t}$ to $r_{t+1}$ and using simple algebra. As in the case of the UIP condition, it is assumed that economic agents do not form fully forward-looking model-consistent expectations. Equation (7) explicitly specifies the expectation formation of the private sector. The share of agents that form model-consistent forward-looking expectations is $\alpha_{71}$, while the rest of the private sector is assumed to approximate real interest rates with one-year maturity with a short-term real interest rate based on backward-looking inflation expectations.

Equation (8) specifies the reaction function of the central bank in a fairly general form. The variables are determined by the state space representation of the model outlined above (see later for details). The coefficients of the optimal policy rules

7) These coefficients can be obtained by a generalisation of the approach presented by Blake (2000). crude.

8) See Söderlind (1999). The approximation for interest rates of such short maturity is, of course, very 
corresponding to various loss functions of policymakers ${ }^{9}$ ) will be derived later using dynamic programming. Equation (9) is a recursive definition of the real exchange rate. Equations (10) - (14) approximate, respectively, the risk premium, imported inflation, foreign inflation measured in terms of the GDP deflator, administered price inflation and foreign demand as simple $A R(1)$ processes.

\section{State Space Representation of the Model}

Given that the model described above is log-linear, it can be transformed into the following state-space form representation: ${ }^{10}$

$$
\left[\begin{array}{c}
X_{t+1} \\
E_{t}\left(x_{t+1}\right)
\end{array}\right]=A \cdot\left[\begin{array}{c}
X_{t} \\
X_{t}
\end{array}\right]+B \cdot i_{t}+\left[\begin{array}{c}
\varepsilon_{t+1} \\
0
\end{array}\right]
$$

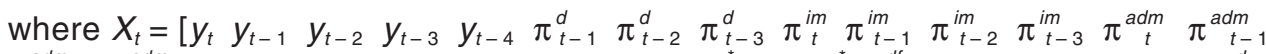

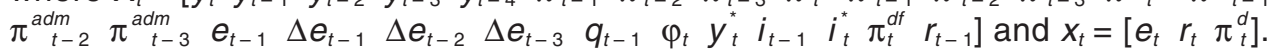
$A$ is a $30 \times 30$ matrix, and $B$ is a $30 \times 1$ vector. Vector $X_{t}$ is sometimes referred to as the state vector, and $x_{t}$ is the vector of forward-looking variables.

One of the simplest ways of setting up the state space representation is to code up the model in the following form:

$$
A 1 \cdot\left[\begin{array}{c}
X_{t+1} \\
E_{t}\left(x_{t+1}\right)
\end{array}\right]=A 2 \cdot\left[\begin{array}{c}
X_{t} \\
X_{t}
\end{array}\right]+B 1 \cdot i_{t}+\left[\begin{array}{c}
\varepsilon_{t+1}^{1} \\
0
\end{array}\right]
$$

where $A 1$ and $A 2$ are $30 \times 30$ matrices, and $B 1$ is a $30 \times 1$ vector. If $A 1$ is a non-singular matrix, $\left(1^{*}\right)$ can be obtained from $\left(1^{* *}\right)$ by simply multiplying both sides of $\left(1^{* *}\right)$ by $A 1^{-1}$.

In order to derive the optimal monetary policy rules corresponding to alternative loss functions of the central bank, the central bank's preferences must first be determined. For the purposes of this paper it is assumed that the central bank's goal is to minimise fluctuations in inflation around the inflation target and to minimise the volatility of the output gap and the change in short-term interest rates. The model specified above is constructed so that various "optimal"11) interest rate rules can be derived (with respect to the volatility of inflation, output, and the change in shortterm interest rates) according to central bank preferences. ${ }^{12)}$ The mathematical expression of the loss function $L_{t}$ is therefore as follows:

$$
L_{t}=w_{\pi^{c p i}} \cdot \pi_{t}^{c p i^{2}}+w_{y} \cdot y_{t}^{2}+w_{\Delta i} \cdot\left(i_{t}-i_{t-1}\right)^{2}
$$

9) The choice of the loss function will be discussed later.

10) I primarily use symbols and derivations according to Svensson (1999).

11) The word "optimal" in the sense above is normative in nature. The central bank decides on preferences in this model (e.g. higher or lower volatility of inflation or product when deriving monetary rules). The objective function of the monetary authorities is not derived on the basis of knowledge of the economic agents' utility function. For an example of a paper in which the loss function is derived from microeconomic principles, see Rotemberg and Woodford (1998).

12) Of course, some other variables, for instance the real exchange rate (one of the important determinants of the current account balance), could also be included in the loss function. 
Since the analytic solution technique to be applied later requires the model to be expressed in a general matrix form, $\left.{ }^{13}\right) L_{t}$ must be expressed as a function of the state vector. Since the variables entering into the loss functions are linear functions of the state vector and the loss function itself is a quadratic function, the general representation of the loss function is given by the following two equations:

$$
\begin{gathered}
Y_{t}=C_{Z} \cdot\left(\begin{array}{ll}
X_{t}^{\prime} & \left.x_{t}^{\prime}\right)+C_{i} \cdot i_{t} \\
L_{t}=Y_{t}^{\prime} \cdot K \cdot Y_{t}
\end{array}\right.
\end{gathered}
$$

where $Y_{t}^{\prime}=\left(\pi_{t}^{c p i} y_{t} i_{t}-i_{t-1}\right), C_{z}$ is a $3 \times 30$ matrix, $C_{i}$ is a $3 \times 1$ column vector, and $K$ is a $3 \times 3$ diagonal matrix with diagonal $\left(\begin{array}{lll}w_{\pi^{c i}} & w_{y} & w_{\Delta i}\end{array}\right)$.

Minimising the loss function defined above is equivalent to finding the minima

$$
T L_{t}=\lim _{\delta \rightarrow 1} E_{t} \sum_{l=0}^{\infty} \delta^{\prime} L_{t+l}
$$

where $\delta$ is a discount factor. Equations $\left(1^{*}\right)-\left(4^{*}\right)$ give a complete description of the model, and therefore the general representation of the solution has the following form:

$$
\begin{gathered}
X_{t+1}=M_{11} \cdot X_{t}+M_{12} \cdot \varepsilon_{t+1} \\
X_{t}=H \cdot X_{t} \\
i_{t}=f \cdot X_{t} \\
Y_{t}=\left(C_{Z}^{1}+C_{Z}^{2} \cdot H+C_{1} \cdot f\right) \cdot X_{t}
\end{gathered}
$$

where $M_{11}$ and $M_{12}$ are $27 \times 30$ matrices, $H$ is a $3 \times 27$ vector, $f$ is a $1 \times 27$ vector, and

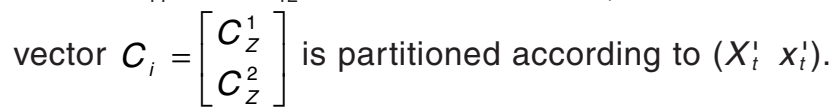

Equation (i) describes the dynamics of the state vector, (ii) expresses the forward-looking variable as a linear combination of predetermined variables, (iii) is an optimal interest rate rule and (iv) is an expression of the variables in the loss function as a linear function of the state vector. Equations (i) and (iv) can be easily derived with the help of (ii), (iii) and $\left(1^{*}\right)-\left(2^{*}\right)$. Equations (i) - (iv) determine the dynamics of the whole system. The interest rate rule (corresponding to the chosen loss function) ensures the model converges to the steady state for any shock hitting the system. The solution is obtained by applying dynamic programming. A detailed description of the optimising algorithm used can be found in Svensson (1999). The program for solving the model was coded up by the author in GAUSS.

\section{Parameterisation of the Model}

In order to be able to solve the model and carry out dynamic impulse response analysis, all parameters in equations (1) - (14) must be determined. For the calibration exercise, the equilibrium values for the stationary variables were set equal

13) Simple matrix algebra is needed to code up the optimising algorithm in GAUSS. 
to their long-term averages. For non-stationary variables a generalised form of the Hodrick-Prescott filter (see Laxton, 1992) was applied in order to incorporate expert judgement into the calibration process and mitigate the poor end-of-sample properties of the HP filter. ${ }^{14)}$ The model parameters of equations (1) -(14) were set as follows:

$$
\begin{aligned}
& \alpha_{11}=0.9, \alpha_{12}=-0.25, \alpha_{13}=0.15, \alpha_{14}=0.25 \\
& \alpha_{21}=0.107, \alpha_{22}=0.282, \alpha_{23}=0.173, \alpha_{24}=0.063, \alpha_{25}=0.0434, \alpha_{26}=0.0359, \\
& \alpha_{27}=0.0214, \alpha_{28}=0.0075, \alpha_{29}=-0.008, \alpha_{210}=0.066, \alpha_{211}=0.056, \alpha_{212}=0.034, \\
& \alpha_{213}=0.013, \alpha_{214}=-0.011, \alpha_{215}=0.087, \alpha_{216}=0.074, \alpha_{217}=0.046, \alpha_{218}=0.017, \\
& \alpha_{31}=0.68, \alpha_{32}=0.14 ; \\
& \alpha_{41}=-0.25, \alpha_{42}=0.25 \\
& \alpha_{51}=0.4 ; \\
& \alpha_{61}=0.8, \alpha_{62}=0.2, \alpha_{63}=-0.8 ; \\
& \alpha_{71}=0.4 ; \\
& \alpha_{101}=0.6, \alpha_{111}=0.09, \alpha_{121}=0.54, \alpha_{131}=0, \alpha_{141}=0.69 ; \alpha_{151}=0.9 .
\end{aligned}
$$

The IS curve elasticities were obtained by simple OLS for the period of 1994:Q1 - 2001:Q4 and are broadly in line with similar estimates reported in previous studies for the Czech Republic (see, for instance, Kotlán, 2002 or Isard and Laxton, 2000). The parameter values entering into the Phillips curve, $\alpha_{21}-\alpha_{218}$, were calibrated using the theoretically derived "deep" parameters for $\alpha_{21}-\alpha_{218}$, expressed in terms of the coefficients of, and derived from, equations (15) - (17). The calibration of the parameters was obtained by applying a numeric non-linear optimising algorithm in a standard Excel spreadsheet. The algorithm minimises ${ }^{15}$ ) the square of the residuals in equation (2) with respect to linear restrictions that all parameters in equations (15) - (17) are positive and the share of administered prices in the CPI basket is known (0.18). In addition it is assumed that the share $\chi_{0}$ of forward-looking agents in wage-contracting equation (17) is $0.10 .{ }^{16)}$ The main reasons for calibrating equation (2) by means of constrained optimisation are the following:

- to be able to derive the parameters of the wage-contracting equation implicitly without relying too much on labour market data, which are very short and subject to changes in data collection methodology over time;

- to obtain plausible parameter values that are consistent both with the theory applied and with the available data as far as possible.

The results of the constrained optimisation in terms of the parameter values of equations (15) - (17) are as follows:

$\lambda_{1}=0.4, \lambda_{2}=0.33, \lambda_{3}=0.20 ; \alpha=0.68, \beta=0.14$;

14) The modification of the HP filter was coded up in GAUSS.

15) Of course, it might be the case that the minimum found in this way represents a locally minimal solution and not a globally minimal solution. The calibrated value of 0.10 assumes slightly less forwardlooking behaviour in wage negotiations than the estimates for developed industrial countries would suggest.

16) Inflation expectations are not available for a long enough time horizon to test econometrically the share of forward-looking agents in the wage-contracting equation. Of course, for standard estimation procedures instrumental variables could be used. 
$\chi_{0}=0.1, \chi_{1}=0.90, \chi_{2}=0.0 ; \Omega=0.11$;

The obtained parameter values $\lambda_{1} \ldots \lambda_{3}$ of equation (15) suggest that wage costs are gradually transmitted into the price of value added over time. In addition, this lag structure is decreasing step by step.

Parameters $\alpha_{31}$ and $\alpha_{32}$ were calculated using the optimising algorithm briefly described above. The implied share of import prices in the CPI basket is $14 \%$. This share is broadly in line with estimates obtained for other small open economies. ${ }^{17)}$ It is important to note in this respect, however, that taking into account the impact of import prices on the GDP deflator itself (see equation 2) the cumulative impact of import prices on the consumer price index is considerably higher.

The parameters of the uncovered interest rate parity conditions are set exactly according to the arbitrage condition specified for quarterly data. The share of the fully rational forward-looking agents (0.4) and that of the backward-looking agents (0.6) were set so that the model exhibits plausible dynamic properties. An assumption of fully forward-looking agents in the exchange rate determination would make the exchange rate channel very fast and the exchange rate itself very "jumpy". Conversely, a very small weight of forward-looking model-consistent agents in the UIP would weaken the immediate impact of monetary policy on the exchange rate.

The parameters of equation (6) are derived from the arbitrage condition on the financial market for real interest rates with $n$ years of maturity. The decision on the one-year maturity is purely judgmental and based on the volume of extended loans with various maturities. The decision on the large share of agents who base their decision on long-term ex-ante real interest rates relative to those who base their expectation on short-term ex-post real interest rates is also judgmental and based on similar reasoning as in the case of the nominal exchange rate. The autoregressive coefficients of $\alpha_{101}-\alpha_{141}$ were determined by simple OLS.

\section{Model Solution for Phillips Curves with Alter- native Wage Equations and Policy Rules}

The main goal of this section is to present the solution for the two models corresponding with the two alternative wage-contracting equations. The first Phillips-curve specification is the one specified by equation (2) corresponding to parameters $\alpha_{21}-\alpha_{218}$. These parameters were obtained by substituting the results of the constrained optimisation exercise mentioned above in terms of the parameters of equations (15) - (17) into the functional forms of $\alpha_{21}-\alpha_{218}$. The second specification is based on a theoretical assumption that in wage-contracting equation (17), real wages are deflated by the GDP deflator at factor costs instead of the consumer price index. The coefficients and the lag structure in equations (15) - (17) are assumed to be the same in both cases. Replacing CPI inflation with domestic inflation in the wage-contracting equation obviously eliminates entirely the impact of import and administered prices on domestic inflation. The resulting Phillips curve will replace equation (2) in the model and will have the following specification instead:

$$
\begin{gathered}
\pi_{t}^{d}=\alpha_{21} \cdot E_{t}\left(\pi_{t+1}^{d}\right)+\alpha_{22} \cdot \pi_{t-1}^{d}+\alpha_{23} \cdot \pi_{t-2}^{d}+\alpha_{24} \cdot \pi_{t-3}^{d}+ \\
+\alpha_{25} \cdot \pi_{t-4}^{d}+\alpha_{26} \cdot \pi_{t-5}^{d}+\alpha_{27} \cdot y_{t}+\alpha_{28} \cdot y_{t-1}+ \\
+\alpha_{29} \cdot y_{t-2}+\alpha_{210} \cdot y_{t-3}+\omega_{t}
\end{gathered}
$$

\footnotetext{
17) The calibration value used for the United Kingdom is 0.2 (see for instance, Blake, Westaway, 1996).
} 
where

$\alpha_{21}=0.105, \alpha_{22}=0.487, \alpha_{23}=0.299, \alpha_{24}=0.109, \alpha_{25}=0$,

$\alpha_{26}=0.0, \alpha_{27}=0.0513, \alpha_{28}=0.0424, \alpha_{29}=0.0253, \alpha_{210}=0.0089$.

For both Phillips-curve specifications, three optimal rules will be derived that correspond to the following weights in the loss function specified by equation (3):

$$
\begin{aligned}
& -w_{\pi^{c p i}}=0.8, w_{y}=0.1, w_{\Delta i}=0.1, \\
& -w_{\pi^{c p i}}=0.45, w_{y}=0.45, w_{\Delta i}=0.1, \\
& -w_{\pi^{c p i}}=0.1, w_{y}=0.8, w_{\Delta i}=0.1 .
\end{aligned}
$$

Again, the choice of the weights in the loss function is arbitrary and reflects, respectively, a higher, equal and lower emphasis put by the monetary authorities on inflation smoothing relative to output stabilisation. The weight put on short-term interest rate smoothing was chosen in order to obtain a plausible - neither too "jumpy" nor too sluggish - reaction of the central bank to various shocks.

The analytic solution of the models for the unknown policy rule and jump variable parameters corresponding to the two types of wage equation and various loss functions of the central bank are reported in Table 1 and Table 2 below. The first, very straightforward, observation is that the model based on a wage-contracting equation in terms of the GDP deflator results in a much simpler solution, including the functional form of the policy rule, than the model with a wage equation based on the CPI. This is a straightforward implication of replacing import price and administered price inflation and their lagged values in equation (2) with domestic inflation. The second observation is that in the specification of the reaction functions of the central bank, all variables have the expected signs on a cumulative basis. ${ }^{18)}$

\section{Definition of Second-round Effects and their Quantification through Impulse Responses}

As was stressed in the introduction, the main goal of this paper is to quantify the second-round effects of import prices and administered prices on wages and subsequently on inflation measured in terms of both the GDP deflator at factor costs and the CPI. Since the paper concentrates solely on those second-round effects which arise from replacing the CPI in the wage-contracting equation with the GDP deflator at factor cost, for the purposes of this paper the second-round effects on inflation (and other model variables) arising from any shock are defined as the difference between the dynamics of the models corresponding with the two alternative wage-contracting specifications, other things held equal.

The interpretation of the ceteris paribus condition deserves special attention in the case of the policy rule. There were at least two possible ways of handling this problem. The first option is to assume that the reaction function of the central bank is unchanged in terms of a simple backward-looking Taylor-type rule. In this case, the change in the Phillips-curve specification would not have any effect on the functional form of the reaction function of the central bank. It is sufficient, however, to include any jump variable in the reaction function ${ }^{19)}$ and the change in the Phillips

18) The sum of elasticities for all current and lagged variables.

19) For instance, a Taylor-type forward-looking inflation forecast based rule would be a good example of such a reaction function. 
Table 1

Model Solution with the Wage Contracting Equation based on CPI

\begin{tabular}{|c|c|c|c|c|c|c|c|c|c|c|c|c|c|c|c|c|c|c|c|c|c|c|c|c|c|c|c|}
\hline Vector & $\Psi_{1}$ & $\Psi_{2}$ & $\Psi_{3}$ & $\Psi_{4}$ & $\Psi_{5}$ & $\Psi_{6}$ & $\Psi_{7}$ & $\Psi_{8}$ & $\Psi_{9}$ & $\Psi_{10}$ & $\Psi_{11}$ & $\Psi_{12}$ & $\Psi_{13}$ & $\Psi_{14}$ & $\Psi_{15}$ & $\Psi_{16}$ & $\Psi_{17}$ & $\Psi_{18}$ & $\Psi_{19}$ & $\Psi_{20}$ & $\Psi_{21}$ & $\Psi_{22}$ & $\Psi_{23}$ & $\Psi_{24}$ & $\Psi_{25}$ & $\Psi_{26}$ & $\Psi_{27}$ \\
\hline \multicolumn{28}{|c|}{ Short-term interest rate (policy rule) } \\
\hline $\begin{array}{l}\text { w_cpi }=0.8 \\
\text { w_y }=0.1\end{array}$ & 0.23 & 0.02 & 0.02 & 0.01 & 0.00 & 0.23 & 0.13 & 0.05 & 0.09 & 0.03 & 0.01 & 0.00 & 0.12 & 0.04 & 0.02 & 0.01 & 0.00 & 0.03 & 0.01 & 0.00 & 0.11 & 0.76 & 0.14 & 0.52 & 0.30 & 0.16 & -0.06 \\
\hline $\begin{array}{l}\text { w_cpi }=0.45 \\
\text { w_y }=0.45\end{array}$ & 0.43 & 0.01 & 0.01 & 0.00 & 0.00 & 0.23 & 0.15 & 0.06 & 0.05 & 0.02 & 0.01 & 0.00 & 0.06 & 0.02 & 0.01 & 0.00 & 0.00 & 0.02 & 0.01 & 0.00 & 0.18 & 0.84 & 0.24 & 0.46 & 0.32 & 0.24 & -0.12 \\
\hline $\begin{array}{l}w_{-} \text {cpi }=0.1 \\
w_{-} y=0.8\end{array}$ & 0.56 & 0.01 & 0.01 & 0.00 & 0.00 & 0.22 & 0.15 & 0.06 & 0.02 & 0.01 & 0.00 & 0.00 & 0.03 & 0.01 & 0.00 & 0.00 & 0.00 & 0.01 & 0.00 & 0.00 & 0.21 & 0.87 & 0.29 & 0.43 & 0.33 & 0.28 & -0.15 \\
\hline \multicolumn{28}{|c|}{ Nominal exchange rate } \\
\hline $\begin{array}{l}\text { w_cpi }=0.8 \\
w_{-} y=0.1\end{array}$ & -0.25 & -0.02 & -0.02 & -0.01 & 0.00 & -0.23 & -0.12 & -0.04 & $\mid-0.07$ & -0.02 & -0.01 & 0.00 & -0.08 & $-0.03 \mid$ & -0.01 & 0.00 & 1.00 & -0.02 & -0.01 & 0.00 & $-0.17 \mid$ & 1.66 & $|-0.17|$ & -0.25 & 0.46 & $-0.27 \mid$ & 0.06 \\
\hline $\begin{array}{l}w_{-} \text {cpi }=0.45 \\
w_{-} y=0.45\end{array}$ & -0.37 & -0.01 & -0.01 & 0.00 & 0.00 & -0.22 & -0.13 & -0.05 & -0.04 & -0.01 & -0.01 & 0.00 & -0.04 & -0.02 & -0.01 & 0.00 & 1.00 & -0.01 & -0.01 & 0.00 & -0.22 & 1.59 & -0.23 & -0.19 & 0.44 & -0.35 & 0.10 \\
\hline $\begin{array}{l}w_{-} \text {cpi }=0.1 \\
w_{-} y=0.8\end{array}$ & -0.43 & -0.01 & -0.01 & 0.00 & 0.00 & -0.22 & -0.13 & -0.05 & -0.02 & -0.01 & 0.00 & 0.00 & -0.03 & -0.01 & 0.00 & 0.00 & 1.00 & -0.01 & 0.00 & 0.00 & -0.24 & 1.56 & -0.27 & -0.17 & 0.44 & -0.38 & 0.12 \\
\hline \multicolumn{28}{|c|}{ Long-term real interest rates } \\
\hline $\begin{array}{l}w_{\text {_ }} \text { cpi } \\
w_{-} y=0.8\end{array}$ & 0.21 & -0.08 & -0.05 & -0.02 & -0.01 & -0.97 & -0.75 & -0.50 & -0.08 & -0.08 & -0.04 & -0.01 & -0.10 & -0.11 & -0.05 & -0.01 & 0.00 & -0.08 & -0.04 & -0.01 & 0.18 & 0.53 & 0.19 & 0.44 & 0.26 & 0.28 & -0.07 \\
\hline $\begin{array}{l}\text { w_cpi }=0.45 \\
w_{-} y=0.45\end{array}$ & 0.41 & -0.09 & -0.06 & -0.03 & -0.01 & -0.97 & -0.74 & -0.48 & -0.13 & -0.10 & -0.05 & -0.01 & -0.16 & -0.13 & -0.06 & -0.02 & 0.00 & -0.10 & -0.05 & -0.01 & 0.26 & 0.63 & 0.30 & 0.36 & 0.28 & 0.39 & -0.13 \\
\hline $\begin{array}{l}w_{-} \text {cpi }=0.1 \\
w_{-} y=0.8\end{array}$ & 0.52 & -0.10 & -0.07 & -0.03 & -0.01 & -0.98 & -0.73 & -0.48 & -0.15 & -0.10 & -0.05 & -0.01 & -0.19 & -0.14 & -0.07 & -0.02 & 0.00 & -0.10 & -0.05 & -0.01 & 0.29 & 0.68 & 0.36 & 0.33 & 0.29 & 0.43 & -0.16 \\
\hline \multicolumn{28}{|c|}{ Domestic inflation } \\
\hline $\begin{array}{l}\text { For all loss } \\
\text { functions }\end{array}$ & -0.02 & 0.05 & 0.04 & 0.02 & 0.01 & 0.30 & 0.18 & 0.06 & 0.07 & 0.06 & 0.04 & 0.01 & 0.10 & 0.08 & 0.05 & 0.02 & 0.00 & 0.06 & 0.04 & 0.01 & -0.02 & 0.12 & -0.02 & -0.01 & 0.03 & -0.03 & 0.01 \\
\hline
\end{tabular}




\section{$\overrightarrow{\boldsymbol{\omega}} \quad$ Table 2 \\ N Model Solution with the Wage Contracting Equation based on the GDP Deflator}

\begin{tabular}{|c|c|c|c|c|c|c|c|c|c|c|c|c|c|c|c|c|c|c|}
\hline Vector & $\Psi_{1}$ & $\Psi_{2}$ & $\Psi_{3}$ & $\Psi_{4}$ & $\Psi_{5}$ & $\Psi_{6}$ & $\Psi_{7}$ & $\Psi_{8}$ & $\Psi_{9}$ & $\Psi_{10}$ & $\Psi_{11}$ & $\Psi_{12}$ & $\Psi_{13}$ & $\Psi_{14}$ & $\Psi_{15}$ & $\Psi_{16}$ & $\Psi_{17}$ & $\Psi_{18}$ \\
\hline \multicolumn{19}{|c|}{ Short-term interest rate (policy rule) } \\
\hline $\begin{array}{l}\text { w_cpi }=0.8 \\
w_{-} \_y=0.1\end{array}$ & 0.39 & 0.07 & 0.04 & 0.02 & 0.01 & 0.63 & 0.33 & 0.10 & 0.03 & 0.04 & 0.00 & 0.15 & 0.72 & 0.20 & 0.50 & 0.28 & 0.22 & -0.09 \\
\hline $\begin{array}{l}\text { w_cpi }=0.45 \\
\text { w_y }=0.45\end{array}$ & 0.54 & 0.05 & 0.03 & 0.01 & 0.00 & 0.51 & 0.28 & 0.09 & 0.02 & 0.02 & 0.00 & 0.20 & 0.81 & 0.27 & 0.46 & 0.30 & 0.27 & -0.14 \\
\hline $\begin{array}{l}\text { w_cpi }=0.1 \\
\text { w_y }=0.8\end{array}$ & 0.61 & 0.03 & 0.02 & 0.01 & 0.00 & 0.38 & 0.22 & 0.08 & 0.00 & 0.00 & 0.00 & 0.22 & 0.84 & 0.31 & 0.44 & 0.31 & 0.29 & -0.16 \\
\hline \multicolumn{19}{|c|}{ Nominal exchange rate } \\
\hline $\begin{array}{l}\text { w_cpi }=0.8 \\
\text { w y }=0.1\end{array}$ & -0.43 & -0.08 & -0.05 & -0.02 & -0.01 & -0.68 & -0.34 & -0.10 & -0.02 & -0.02 & 1.00 & -0.22 & 1.66 & -0.23 & -0.22 & 0.47 & -0.36 & 0.10 \\
\hline $\begin{array}{l}\text { w_cpi }=0.45 \\
\text { w_y }=0.45\end{array}$ & -0.48 & -0.05 & -0.03 & -0.01 & 0.00 & -0.54 & -0.28 & -0.09 & -0.01 & -0.01 & 1.00 & -0.25 & 1.60 & -0.27 & -0.18 & 0.46 & -0.39 & 0.12 \\
\hline $\begin{array}{l}\text { w_cpi }=0.1 \\
w_{-} y=0.8\end{array}$ & -0.50 & -0.04 & -0.02 & -0.01 & 0.00 & -0.42 & -0.23 & -0.08 & 0.00 & 0.00 & 1.00 & -0.26 & 1.58 & -0.29 & -0.17 & 0.45 & -0.41 & 0.13 \\
\hline \multicolumn{19}{|c|}{ Long-term real interest rates } \\
\hline $\begin{array}{l}\text { w_cpi }=0.8 \\
w_{-} y=0.1\end{array}$ & 0.26 & -0.09 & -0.07 & -0.03 & -0.01 & -1.34 & -0.95 & -0.55 & 0.03 & 0.03 & 0.00 & 0.17 & 0.82 & 0.20 & 0.38 & 0.35 & 0.25 & -0.08 \\
\hline $\begin{array}{l}\text { w_cpi }=0.45 \\
\text { w_y }=0.45\end{array}$ & 0.37 & -0.12 & -0.08 & -0.04 & -0.01 & -1.47 & -1.01 & -0.56 & 0.01 & 0.01 & 0.00 & 0.21 & 0.91 & 0.26 & 0.33 & 0.37 & 0.30 & -0.12 \\
\hline $\begin{array}{l}\text { w_cpi }=0.1 \\
\text { w_y }=0.8\end{array}$ & 0.43 & -0.14 & -0.10 & -0.05 & -0.01 & -1.61 & -1.06 & -0.58 & 0.00 & 0.00 & 0.00 & 0.23 & 0.94 & 0.30 & 0.31 & 0.38 & 0.33 & -0.14 \\
\hline \multicolumn{19}{|c|}{ Domestic inflation } \\
\hline $\begin{array}{l}\text { For all loss } \\
\text { functions }\end{array}$ & 0.01 & 0.06 & 0.05 & 0.03 & 0.01 & 0.55 & 0.33 & 0.12 & 0.00 & 0.00 & 0.00 & 0.00 & 0.00 & 0.00 & 0.00 & 0.00 & 0.00 & 0.00 \\
\hline
\end{tabular}


curve would result in a change in the rule itself, since the rule would be a function of all state variables and model parameters. The second option - the one ultimately chosen by the author - is to assume that the preferences of the monetary authorities expressed in terms of the loss function are unchanged. ${ }^{20)}$ However, given that the optimal rules corresponding to an unchanged loss function are different for different Phillips-curve specifications, this means that the functional specification of the optimal rule will be different for all simulations (see the results presented in Tables 1 and 2).

In order to quantify the second-round effects on inflation and other model variables arising from selected supply-side and asset-price shocks, two different impulse response exercises were generated for the three policy rules corresponding with the hypothetical loss functions of the central bank specified in the previous section. The first impulse response includes a 100 basis point shock to import prices expressed in foreign currency; the second shock, of the same magnitude, is generated with respect to the nominal exchange rate. There are two good reasons for carrying out impulse responses for these variables. First, despite the fact that both shocks result in a 100 basis point change in import prices, their implications for the models' dynamics are dramatically different. A shock to import prices (expressed in foreign currency) transmits directly into consumer price inflation and through wage contracts indirectly into domestic inflation. In the case of a shock to the nominal exchange rate, in addition to the direct and indirect import price effect there is a strong demand effect caused by the change in the real exchange rate. The two impulse responses, therefore, illustrate how important it is for the monetary authorities to differentiate between the shocks hitting the economy to be able to react adequately. The second reason for generating a shock to import prices (expressed in foreign currency) is motivated by the almost identical effect of this shock (although with slightly different magnitude and inertia) on the models' dynamics to the shock to administered prices. ${ }^{21)}$ Therefore, the impulse response exercise for import prices results in a very similar dynamic response of the model as for a shock to administered prices.

The dynamic properties of the models based on the two Phillips curves corresponding with the alternative wage-contracting equations are depicted in Figures 1 -4 by generating a 100 basis point shock to import prices and the nominal exchange rate. Figures 1 and 2 aim at comparing the dynamic response of the two models to the two shocks given a loss function with fixed equal weights for both inflation and output $w_{\pi^{c p i}}=0.45, w_{y}=0.45, w_{\Delta i}=0.1$.

As such, these impulse response results are useful in terms of understanding the dynamic response to the shocks of the models with the two alternative wagecontracting equations and comparing the results for the same loss function of the central bank. Figures 3 and 4 concentrate solely on the second-round effects arising from these shocks for the three models corresponding with the considered alternative loss functions of the central bank. Therefore, these simulations are intended to illustrate the impact of the choice of a particular loss function of the central bank on the magnitude of the second-round effect for the main model variables.

20) The final choice between the two alternatives also reflects the view presented by Svensson (2002), who prefers fixing a general targeting rule of the central bank instead of the monetary policy rule itself. A policy rule corresponding with an unchanged loss function is an example of such a targeting rule.

21 ) It is easy to see that administered and import prices enter symmetrically into both the CPI and Phillips-curve equations. 


\section{1 Temporary 100 Basis Point Shock to Import Prices - Comparing the Models' Dynamics for the two Phillips Curves Corresponding with the Alternative Wage-contracting Equations}

The 100 basis point shock to import prices results in a jump of consumer price inflation due to the direct import price channel (see 1G) that in turn initiates a reaction of the central bank by increasing short-term nominal interest rates (see $1 \mathrm{~A})$. This reaction is slightly stronger when wage contracting is based on consumer wages. At the same time, consumer price inflation falls after the one-time jump almost immediately back to target when nominal wage contracts are derived from real product wages. The alternative wage specification results in considerably higher consumer price inflation with more inertia. This is simply a consequence of the Phillips-curve specifications specified for domestic inflation (equations (2) and (2')). When wage contracting is based on real wages in terms of domestic inflation (equation (2')), import prices do not directly influence domestic inflation. This is in contrast with the case where the Phillips curve is derived from a wage-contracting equation based on real consumer wages (equation (2)). Import prices in this case do have a significant and inertial effect on domestic inflation. Figure $1 \mathrm{H}$ depicts the difference between the two cases.

The other significant difference between the dynamics of the two alternative models involves the channels by which the inflationary impact of the supply-side shock is reduced by the central bank. When wage contracts are based on consumer wages, monetary conditions are tightened through the real appreciation of the exchange rate. Real interest rates are for most of the disinflation process below their equilibrium value. When, on the contrary, wage contracts are based on real product wages, the elimination of inflationary pressures is carried out by means of an increase of real interest rates above their equilibrium level. The level of real interest rates more than eliminates the expansionary impact of the real exchange rate (see $1 \mathrm{C}$ and 1D). The combined effect of the real exchange rate and real interest rate on demand is shown in 1B. In order to bring inflation back to target the monetary authorities maintain tighter monetary conditions when import prices do have a direct impact on nominal wage contracts (and subsequently on domestic inflation) in comparison with the alternative wage specification.

\section{2 Temporary 100 Basis Point Shock to the Nominal Exchange Rate - Comparing the Models' Dynamics for the two Phillips Curves Corre- sponding with the Alternative Wage-contracting Equations}

A 100 basis point shock to the nominal exchange rate, similarly as in the previous case, results in a jump in import prices and subsequently in consumer price inflation. The reaction of the central bank to the shock, however, is considerably stronger than in the previous case: the initial jump in short-term interest rates is about five times higher. It is important to bear in mind that the change in the nominal exchange rate (see $2 \mathrm{~F}$ ) and real exchange rate (see 2D) in the initial period after the shock generates a strong demand effect (see the specification of the IS curve captured by equation (1)). Therefore, the central bank must increase short-term interest rates considerably in order to react to inflation being above target and curb demand-led inflationary pressures that could accelerate inflation in the future. There are a few transmission channels, however, through which the disinflation is achieved in the models. First, the reaction of the central bank results in an initial rise of long-term real interest rates (see $2 \mathrm{C}$ ), and the real exchange rate (see 2D) falls back to equilibrium too. It should also be noticed that the volatility of both the real inte- 
Figure 1

\section{A Temporary 100 Basis Point Shock to Import Prices}

1A: Short-term Interest Rates

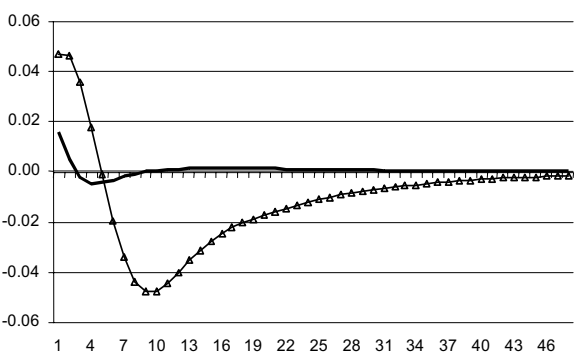

1C: Long-term Real Interest Rates

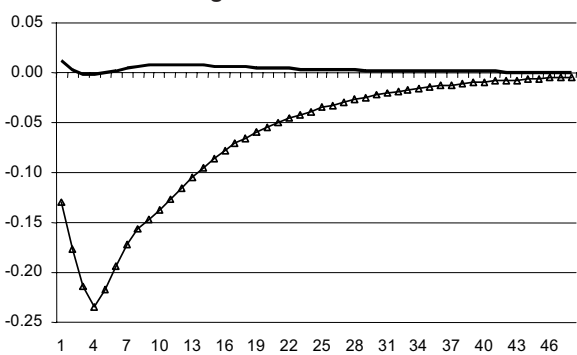

1E: Quarterly Change in the Nominal Exchange Rate

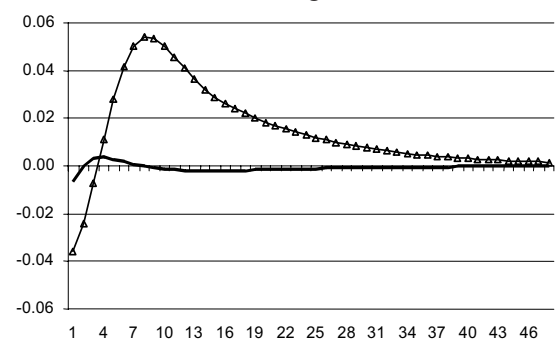

1G: Inflation Measured by CPI

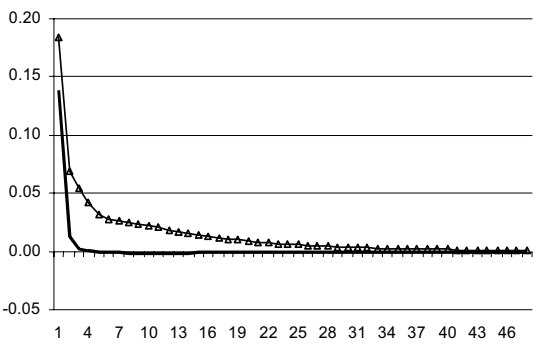

1B: Output

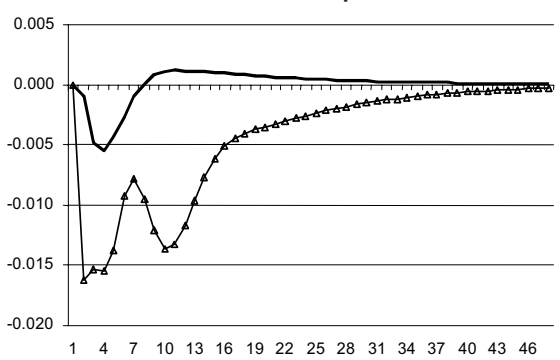

1D: Real Exchange Rate

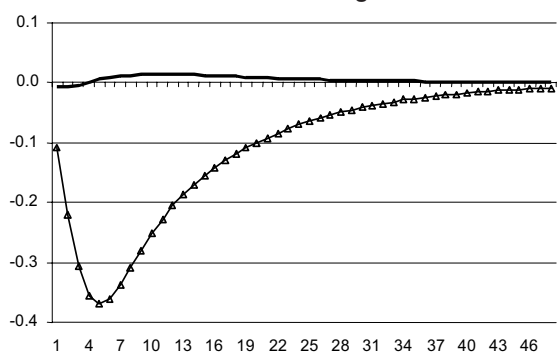

1F: Nominal Exchange Rate

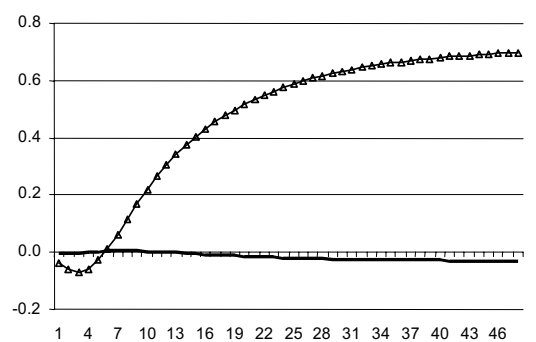

1H: Inflation Measured by the GDP Deflator

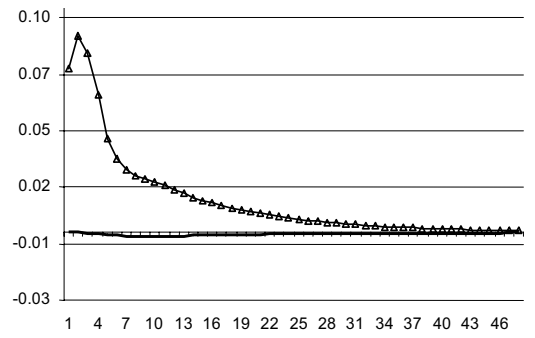


Figure 2

A Temporary 100 Basis Point Shock to the Nominal Exchange Rate

2A: Short-term Interest Rates

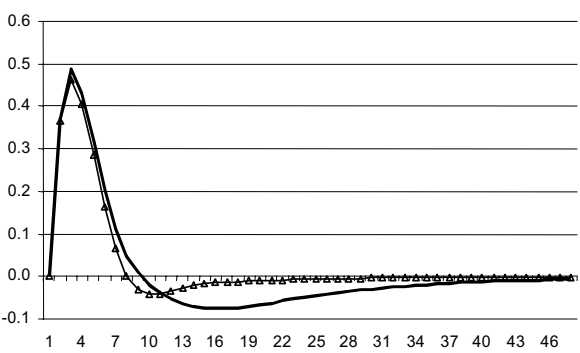

2C: Long-term Real Interest Rates

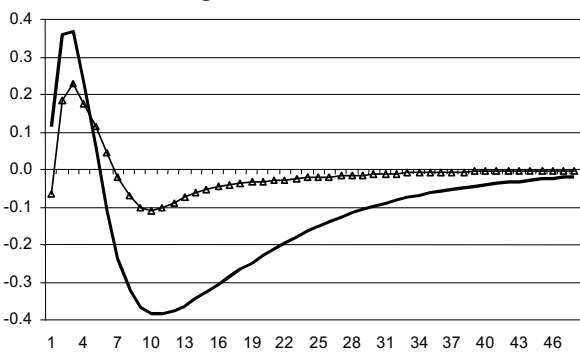

2E: Quarterly Change in the Nominal Exchange Rate

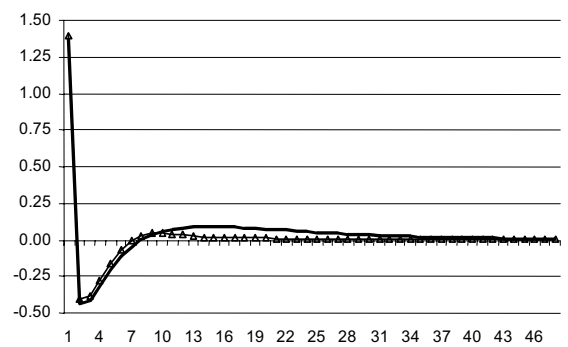

2G: Inflation Measured by CPI

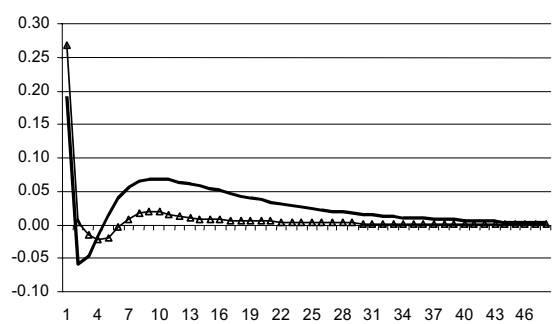

2B: Output

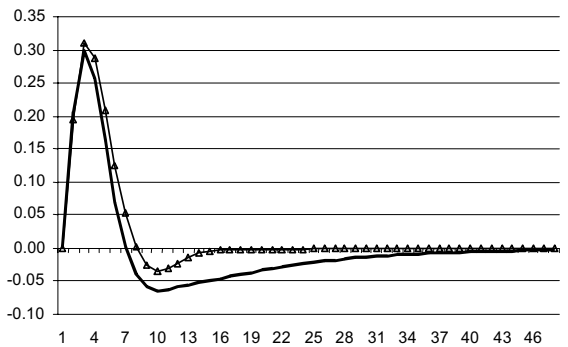

2D: Real Exchange Rate

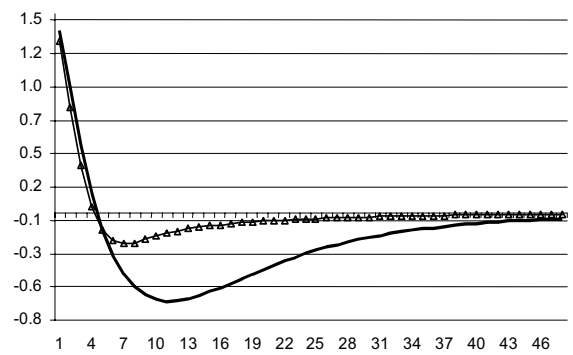

2F: Nominal Exchange Rate

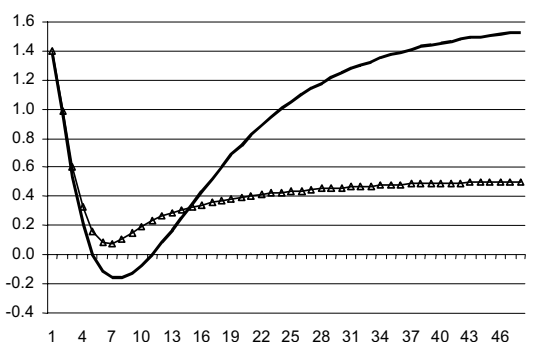

2H: Inflation Measured by the GDP Deflator

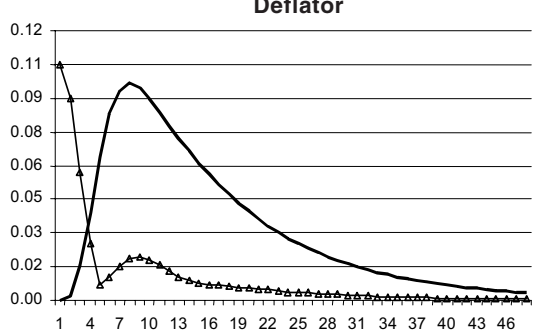


rest rate and the exchange rate is higher when the second-round effects of import prices are absent. The combined effect of the positive real interest rate and appreciating real exchange rate gradually reduces the excess demand (see $2 \mathrm{~B}$ ). The magnitude and dynamics of the output gap, despite the differences in the dynamics of the real exchange rate and real interest rate, are similar for both Phillips-curve specifications.

The visually most significant difference between the two models' dynamics emerges for domestic inflation (see $2 \mathrm{H}$ ). The difference in the specification of the Phillips curves corresponding with the two wage-contracting equations largely explains why domestic inflation is more volatile when wage contracts are derived from real consumer wages as opposed to the real product wage. The reason is that the exchange rate shock feeds into nominal wage contracts and therefore causes greater volatility of domestic inflation at the initial stage. At the same time the appreciation following the shock exerts an anti-inflationary effect on wages and subsequently on domestic inflation. The difference between the two models is somewhat smaller for consumer price inflation (see $2 \mathrm{G}$ ), which can be explained by the very same impact of the change of the nominal exchange rate (see $2 \mathrm{E}$ ) on total inflation in the case of both models.

\section{3 Temporary 100 Basis Point Shock to Import Prices - Quantification of Second-round Effects for the Three Alternative Loss Functions of the Central Bank}

The first very intuitive and straightforward implication of the impulse response results depicted in $3 \mathrm{~A}-3 \mathrm{H}$ is that the magnitude of the second-round effects arising from a 100 basis point shock to import prices is directly linked to the chosen loss function of the central bank. As one would expect, the volatility of the second-round effects for those variables that are included in the loss function of the central bank is negatively related to the weight of that variable in the loss function. Figures $3 \mathrm{~B}$ and $3 G$ clearly support this observation. The volatility of the second-round effects for output is the highest for the loss function with the smallest weight for output, and, similarly, the volatility of the second-round effects for inflation is the highest for the reaction function that puts the smallest emphasis on inflation relative to output smoothing. It should be noticed that when output smoothing is the main priority of the authorities, the second-round effect of the shock on output is close to zero (see 3B). On the contrary, the second-round effects of the shock on CPI and domestic inflation (see $3 \mathrm{G}$ and $3 \mathrm{H}$ ) are positive, different from zero. This can be explained by the specification of the Phillips curve, namely, by the quick transmission of import prices into CPI and domestic inflation. The inflationary impact of the shock can be eliminated by monetary policy only with some delay.

The behaviour of the central bank and correspondingly the dynamics of the nominal exchange rate (see $3 A, 3 E$ and $3 F$ ) is very much in line with simple intuition. The higher is the weight of inflation in the loss function of the central bank, the larger is the initial interest rate hike and corresponding nominal exchange rate appreciation to mitigate the inflationary pressures arising from the shock. The dynamics of the real interest rate and exchange rate (see 3C and 3D) also correspond with the loss-function specification. The highest preference for inflation smoothing results in the lowest real interest rate and most appreciated real exchange rate in the initial period, and vice versa. 
Figure 3

A Temporary 100 Basis Point Shock to Import Prices

3A: Short-term Interest Rates

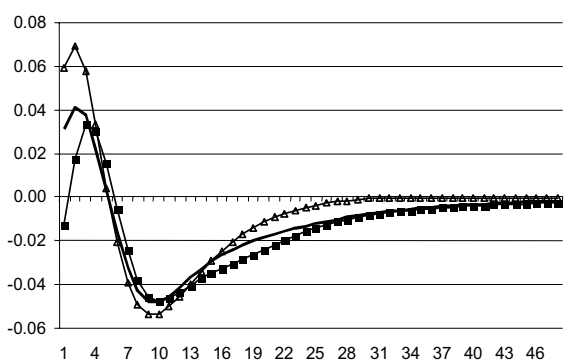

3C: Long-term Real Interest Rates

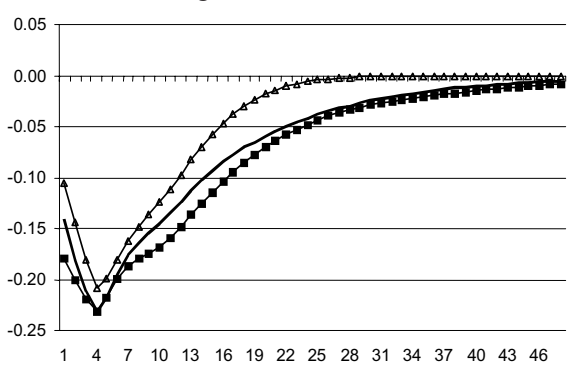

3E: Quarterly Change in the Nominal Exchange Rate

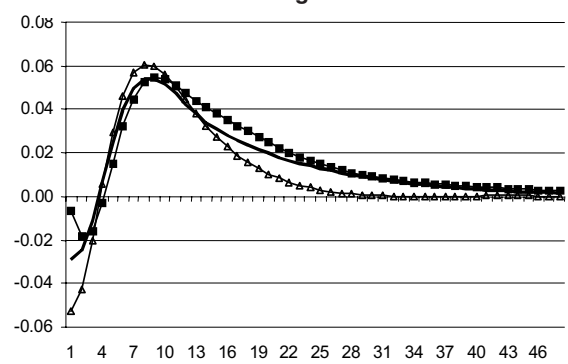

3G: Inflation Measured by CPI

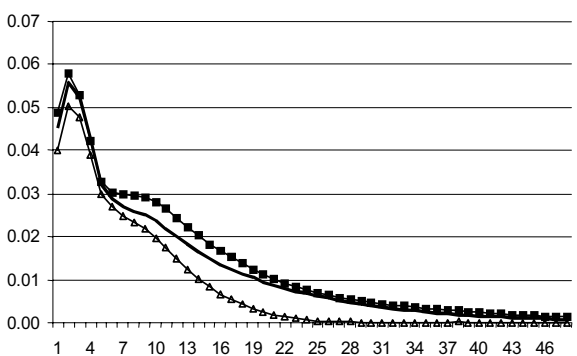

3B: Output

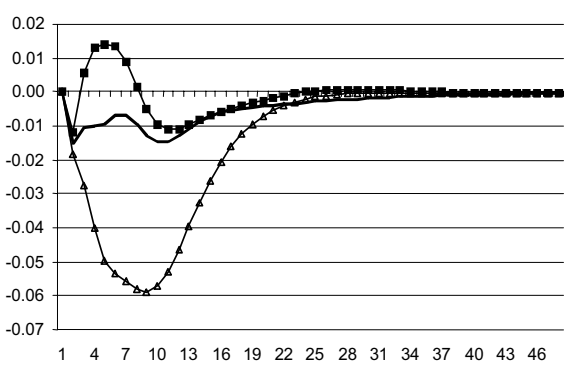

3D: Real Exchange Rate

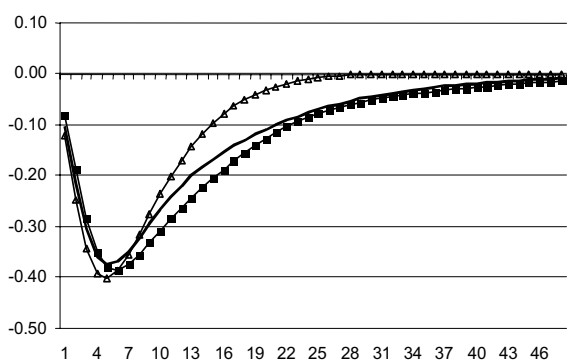

3F: Nominal Exchange Rate

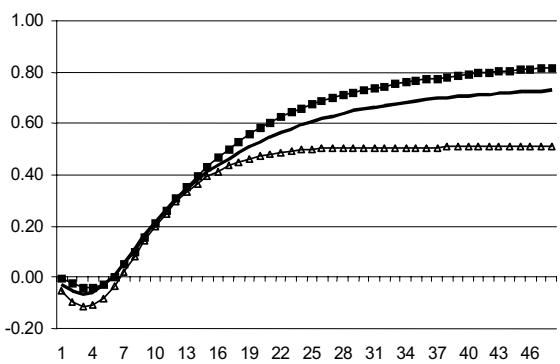

3H: Inflation Measured by the GDP Deflator

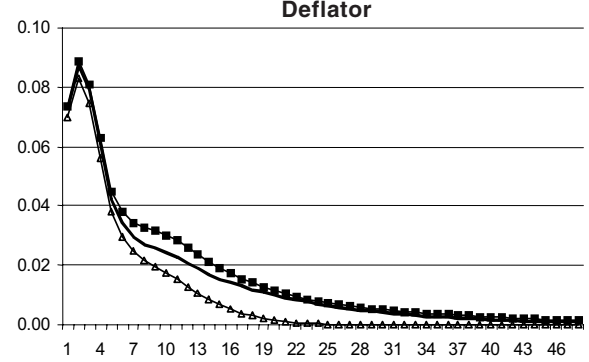

$$
\rightarrow \text { w } \_\mathrm{p} i=0.1 \mathrm{w} \_\mathrm{y}=0.8 \quad \longrightarrow \text { w } \_\mathrm{i}=0.45 \mathrm{w} \_\mathrm{y}=0.45 \quad \longrightarrow \text { w } \_\mathrm{p}=0.8 \mathrm{w} \_\mathrm{y}=0.1
$$


Figure 4

A Temporary 100 Basis Point Shock to the Nominal Exchange Rate

4A: Short-term Interest Rates

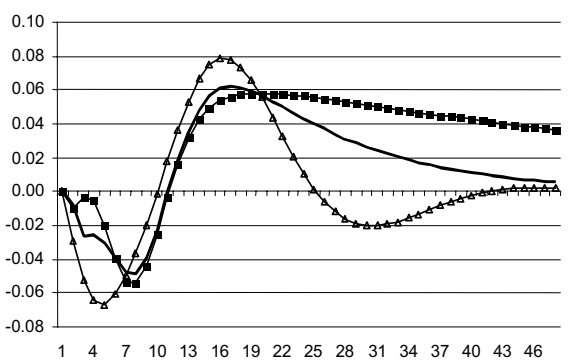

4C: Long-term Real Interest Rates

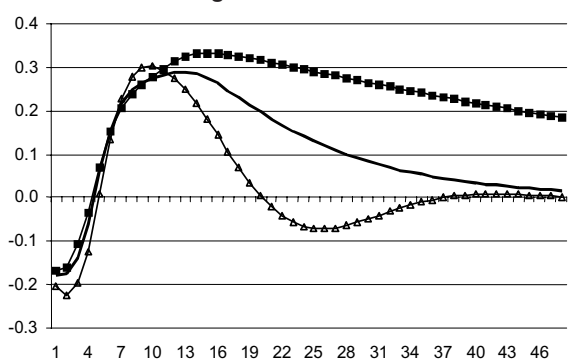

4E: Quarterly Change in the Nominal Exchange Rate

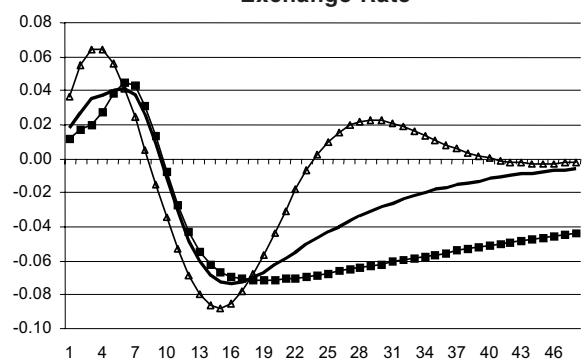

4G: Inflation Measured by CPI

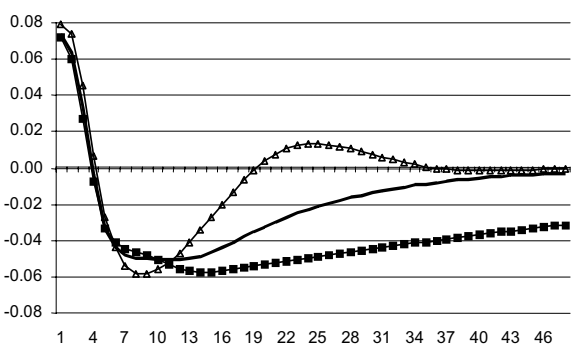

4B: Output

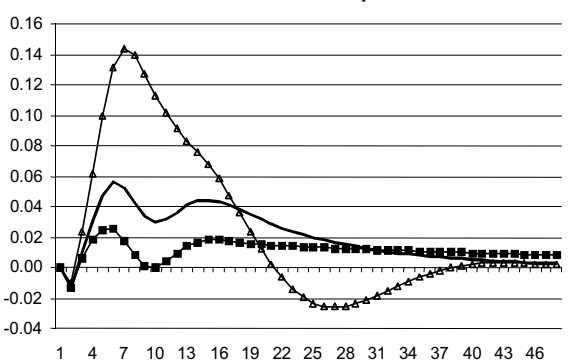

4D: Real Exchange Rate

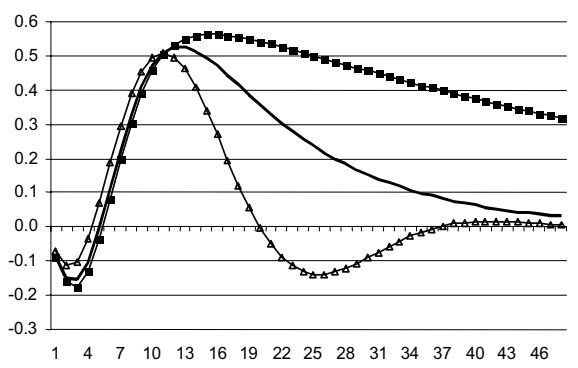

4F: Nominal Exchange Rate

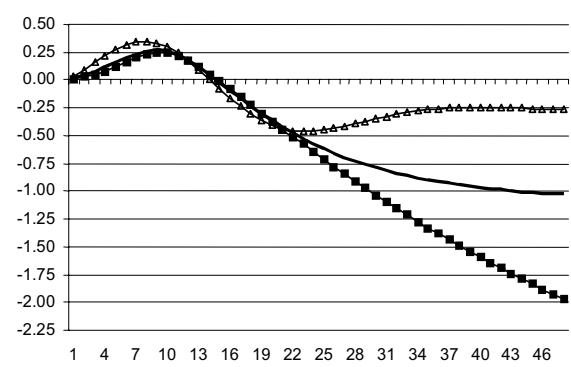

4H: Inflation Measured by the GDP Deflator

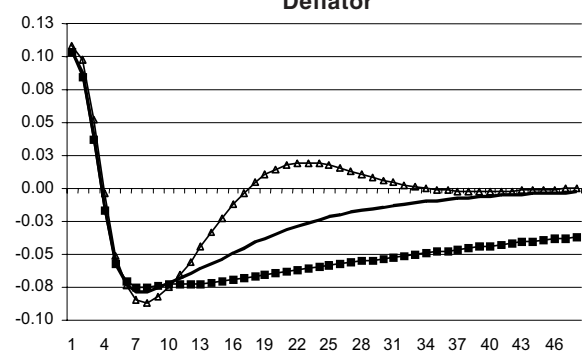

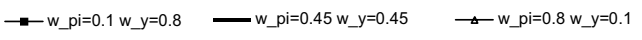




\section{4 Temporary 100 Basis Point Shock to the Nominal Exchange Rate - Quantification of Second-round Effects for the Three Alternative Loss Functions of the Central Bank}

For most variables a temporary 100 basis point shock to the nominal exchange rate results in second-round effects of similar magnitude as in the previous case. The timing of the dynamic response for most variables is, however, different. The dynamic response in 4B illustrates that the initial second-round effects on output are negative ${ }^{22)}$ when the shock hits import prices and, on the contrary, the initial secondround effect on output is positive when the shock is generated for the nominal exchange rate. This difference between the impact of the two shocks stems from their different origin. On the one hand the import price shock has no direct effect on the real exchange rate and subsequently on demand, though it raises inflationary expectations through the direct exchange rate channel. On the other hand the exchange rate shock results in a strong positive impact on the output gap that cannot be entirely and immediately eliminated by the monetary policy reaction.

The evaluation of the second-round effects for the three considered policy rules gives similarly intuitive results as in the case of the previous 100 basis point shock to import prices. The volatility of the second-round effects for inflation and output corresponds with the chosen weight of these variables in the loss function of the central bank. The increasing of output relative to inflation in the loss function weight (from 0.1 to 0.8 ) results in a decreasing volatility of output relative to the volatility of consumer price inflation. Figures $4 \mathrm{G}$ and $4 \mathrm{H}$ illustrate that a small emphasis put on inflation smoothing results in a very gradual return of both consumer and domestic inflation to the steady state.

\section{Conclusion}

The main goal of this paper was to quantify the second-round effects of selected supply-side shocks on inflation depending on alternative assumptions made regarding wage-contracting specifications. The two alternatives included FuhrerMoore-type wage-setting behaviour, with real wages being defined in the first case in terms of the CPI and in the second case in terms of the GDP deflator. A calibrated structural model framework was used for the quantification that incorporates both forward-looking model-consistent and adaptive expectations of economic agents on various markets. The models for the two alternative Phillips-curve specifications specified in terms of domestic inflation were solved for three optimal policy rules corresponding with three different (ad-hoc) loss functions of the central bank.

The dynamic properties of the models were analysed for a temporary 100 basis point shock to import prices and the nominal exchange rate. The impulse response results contained in the paper imply that the second-round effects of these shocks on wages and subsequently on prices are significant enough to be taken into account in monetary policy decisions. The magnitude of the second-round effects of these shocks on inflation and output depends not only on the source of the shocks themselves, but also on the choice of reaction function of the central bank. The simulation results also suggest that the relative magnitude of the second-round effects of the considered shocks on inflation and output is positively related to the weight of these variables in the loss function of the monetary authorities.

22) The only exception is the dynamic response for the model with the policy rule associated with the highest weight for output smoothing. 
References

Batini, N., Haldane, A. (1999), "Forward Looking Rules for Monetary Policy", in Taylor, J. B., Monetary Policy Rules. Chicago: The University of Chicago Press, pp. 157-202.

Batini, N., Yates, A. (2001), "Hybrid Inflation and Price Level Targeting." London, Bank of England, Working Paper No. 135.

Blake, A. (2000), "Optimality and Taylor Rules?" National Institute Economic Review, (174), pp. 8091.

Blake, A. P., Westaway, P. F. (1996), "Credibility and Effectiveness of Inflation Targeting Regimes." Manchester School Supplement, 64, pp. 28-50.

Blanchard, O., Kahn, C. M. (1980), "The Solution of Linear Difference Models Under Rational Expectations." Econometrica 48 (5), pp. 1305-1311.

Fuhrer, J. C., Moore, G. R. (1995), "Inflation Persistence." Quarterly Journal of Economics, 110, pp. 127-159.

Goodfriend, M. (1991), "Interest Rates and the Conduct of Monetary Policy." Carnegie-Rochester Conference Series on Public Policy, 34, pp. 7-30.

Goodhart, C. (1996), "Why do the Monetary Authorities Smooth Interest Rates?" London, London School of Economics, Financial Group Special Papers, SP0081.

Isard, P., Laxton, D. (2000), "Inflation-forecast Targeting and the Role of Macroeconomic Models", in Coats, W., Inflation Targeting in Transition Economies: The Case of the Czech Republic." Prague, Czech National Bank and IMF, pp. 105-146.

King, M. (1996), "How Should Central Banks Reduce Inflation - Conceptual Issues." Bank of England Quarterly Bulletin, 36 (4), pp. 434-448.

Kotlán, V. (2002), "Monetary Policy and the Term Structure of Interest Rates in a Small Open Economy - A Model Framework Approach." Prague, Czech National Bank, Working Paper No. 1.

Laxton, D., Tetlow, R. (1992), "A Simple Multivariate Filter for the Measurement of Potential Output." Bank of Canada, Technical Report No. 59.

Obstfeld, M., Rogoff, K. (1997), Foundations of International Macroeconomics. London, Cambridge, MA: The MIT Press.

Oudiz, G., Sachs, J. (1985), "International Policy Coordination in Dynamic Macroeconomic Models", in Buiter, W., Marston, R., eds., International Economic Policy Coordination. Cambridge: Cambridge University Press, pp. 274-219.

Söderlind, P. (1999), "Monetary Policy and the Fisher Effect." Stockholm School of Economics, Working Paper No. 1594.

Svensson, L. O. (1999), "Open Economy Inflation Targeting." Institute for International Economic Studies Seminar Paper No. 672.

(2002), "Inflation Targeting: Should it Be Modelled as an Instrument Rule or a Targeting Rule?" European Economic Review, 46, pp. 771-780.

Taylor, J. B. (1980), "Aggregate Dynamics and Staggered Contracts." Journal of Political Economy, 88 , pp. 1-24.

(1993), "Discretion versus Policy Rules in Practice." Carnegie-Rochester Conference Series on Public Policy, 39, pp. 195-214.

Rotemberg, J. J., Woodford, M. (1998), "An Optimization-based Econometric Framework for Evaluation of Monetary Policy." Cambridge, MA, NBER, Technical Working Paper No. 233. 